\title{
Erratum to: Proceedings of the Tenth International Conference on Management Science and Engineering Management
}

\author{
Jiuping Xu, Asaf Hajiyev, Stefan Nickel and Mitsuo Gen
}

\section{Erratum to:}

J. Xu et al. (eds.), Proceedings of the Tenth International Conference on Management Science and Engineering Management, Advances in Intelligent Systems and Computing 502, DOI 10.1007/978-981-10-1837-4

The book was inadvertently published without including the editor's name and affiliation in the front matter. The erratum book has been updated with the changes.

The updated original online version for this book frontmatter can be found at 10.1007/978-981-10-1837-4

J. Xu ( ()

Business School, Sichuan University, Chengdu, Sichuan, China

e-mail: xujiuping@scu.edu.cn
A. Hajiyev
Azerbaijan National Academy of Science, Baku, Azerbaijan
e-mail: asaf@baku-az.net
S. Nickel
Karlsruhe Institute of Technology, Karlsruhe, Baden-Württemberg, Germany e-mail: stefan.nickel@kit.edu

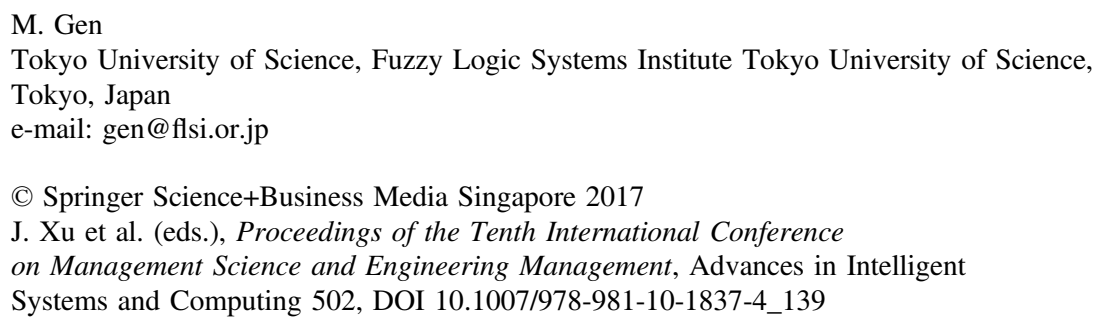

